\title{
Sudden Cardiac Death in Hemodialysis Patients: A Comprehensive Care Approach to Reduce Risk
}

\author{
Patrick H. Pun John P. Middleton \\ Division of Nephrology, Department of Medicine, Duke University School of Medicine, Durham, N.C., USA
}

\section{Key Words}

Sudden cardiac death - Hemodialysis patients •

Implantable cardioverter defibrillators

\begin{abstract}
Sudden cardiac death is a major problem in hemodialysis patients, and our understanding of this disease is underdeveloped. The lack of a precise definition tailored for use in the hemodialysis population limits the reliability of epidemiologic reports. Efforts should be directed toward an accurate classification of all deaths that occur in this vulnerable population. The traditional paradigm of disease pathophysiology based on known cardiac risk factors appears to be inadequate to explain the magnitude of sudden cardiac death risk in chronic kidney disease, and numerous unique cofactors and exposures appear to determine risk in this population. Well-designed cohort studies will be needed for a basic understanding of disease pathophysiology and risk factors, and randomized intervention trials will be needed before best management practices can be implemented. This review examines available data to describe the characteristics of the high-risk patient and suggests a comprehensive common sense approach to prevention using existing cardiovascular medications and reducing and monitoring potential dialysis-related arrhythmic triggers. Other unproven cardiovascular therapies such as implantable cardioverter
\end{abstract}

defibrillators should be used on a case-by-case basis, with recognition of the associated hazards that these devices carry among hemodialysis patients.

Copyright $\odot 2012$ S. Karger AG, Basel

\section{Introduction}

Patients assigned to a regimen of routine hemodialysis face long-term prospects that are harrowing. The annual mortality among hemodialysis patients approaches $20 \%$, and cardiovascular disease accounts for the majority of deaths $[1,2]$. Sudden cardiac death (SCD) accounts for one out of every four deaths and is the greatest single contributor to overall mortality. The purpose of this brief review is to highlight what is known and what remains to be understood about SCD in dialysis patients, and to provide insights into management of this problem based on the current state of evidence.

\section{Epidemiology and Definition of SCD}

The relative risk of SCD is elevated for all patients with chronic kidney disease (CKD), but the risk is increased 20- to 30-fold in hemodialysis patients compared to other populations without significant kidney disease

\section{KARGER \\ Fax +4161306 1234 \\ E-Mail karger@karger.ch}

www.karger.com
(C) 2012 S. Karger AG, Basel

0253-5068/12/0333-0183\$38.00/0

Accessible online at:

www.karger.com/bpu
Patrick H. Pun, MD, MHS

Duke University Medical Center

PO Box 2747

Durham, NC 27710 (USA)

Tel. +1 919660 6865, E-Mail patrick.pun@ duke.edu 
(fig. 1). Current estimates from the United States Renal Data System (USRDS) suggest that SCD accounts for about $22-27 \%$ of all deaths in hemodialysis patients [3]. The first 9 months after a patient initiates a hemodialysis regimen appears to be a particularly high-risk period for SCD [1].

It is important to acknowledge that SCD rates that are reported from registries are closely tied to how SCD is defined, and that determining the cause of death is potentially problematic in hemodialysis patients. The most widely accepted definition of SCD is death from an unexpected circulatory arrest, occurring within an hour of symptom onset, or an unwitnessed, unexpected death in patients known to be well within the past $24 \mathrm{~h}$ without an obvious noncardiac cause [4-6]. Unique problems arise with this definition in dialysis patients. First, a significant proportion of sudden deaths are unwitnessed and clinical information collected around the time is very often limited, making exclusion of a noncardiac cause of sudden death very difficult [7]. Second, determining the unexpectedness of death is problematic in end-stage renal disease patients who are chronically ill, carry a high burden of comorbidities, and are frequently hospitalized and receive care in other health care facilities. Because of these factors, there is lack of consistency in how SCD is defined in hemodialysis patients in the existing literature. For example, cardiac arrests occurring in the setting of withdrawal from dialysis or a missed dialysis treatment have been included as SCD in older studies. These types of occurrences, if known, must be excluded as we seek to identify unique processes that might improve survival in these high-risk patients.

Prior studies also demonstrated the potential for misclassification within administratively derived cause of death data, including the USRDS [8]. In order to examine this issue, we studied potential misclassification in registry data specific to SCD. Using eyewitness accounts of SCD in the dialysis clinic as the reference standard, we found that the sensitivity of the USRDS SCD definition to be $70.8 \%$, rising to $82 \%$ with the use of additional registry data [9]. Similar studies have found the sensitivity of SCD reporting to be $90.7 \%$ [10]. The remarkable consistency of the reported contribution of SCD to all-cause mortality from other data sources such as clinical trials $[11,12]$ and dialysis cohorts $[2,13,14]$ also provides reassurance that registry-reported SCD rates are not a gross over- or underestimation of actual rates. Clinicians and researchers alike should strive for greater accuracy and consistency with existing SCD definitions when reporting SCD events.

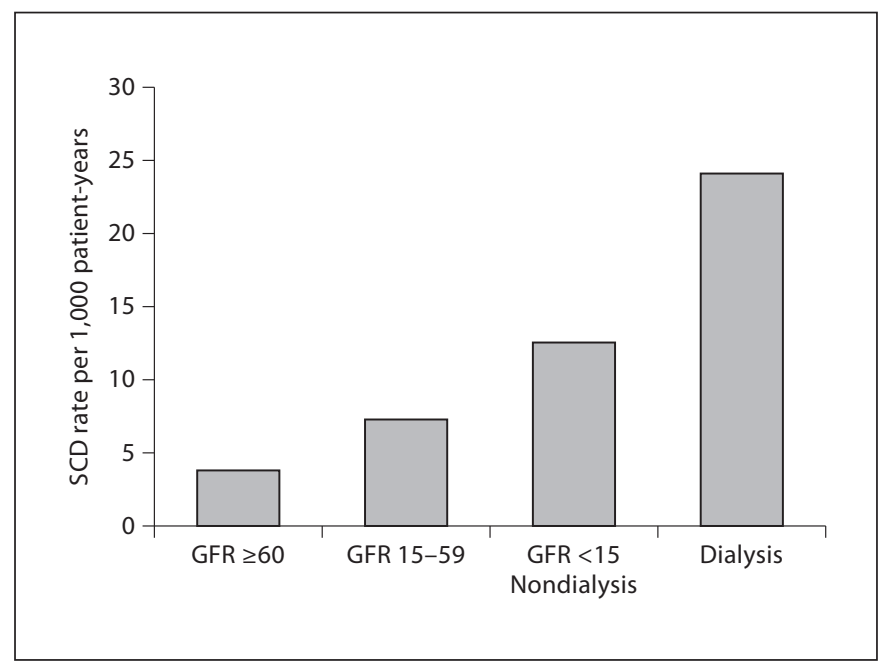

Fig. 1. Risk of SCD by glomerular filtration rate among 19,440 subjects with significant coronary artery disease [51].

\section{Risk Factors and Proposed Mechanisms of SCD in Hemodialysis Patients}

The traditional view of SCD pathophysiology posits a vulnerable, diseased myocardium with a transient arrhythmic trigger [15]. In individuals who lack kidney disease, the substrate for a terminal arrhythmia is most often an ischemic myocardium, a ruptured arterial plaque, a focal myocardial scar, and/or a reduced left ventricular ejection fraction [15]. The most common terminal arrhythmia observed in individuals in the general population who experience SCD is ventricular tachyarrhythmia [15]. Therefore, it stands to reason that conventional coronary risk factors, clinical markers such as ejection fraction, and electrocardiographic variables such as extremes of the QT interval are capable of predicting patients at risk for SCD in the general population [15]. Mutations in susceptibility genes are also associated with SCD in certain settings. Abnormalities in genes that encode a variety of ion channels cause rare inherited disorders such as long QT syndrome, and mutations of other genes such as NOS1AP determine intermediate risk of SCD in certain cohorts within the general population [16].

Whether or not these same risk factors are also predictive of SCD among patients with advanced CKD has not been fully addressed. However, consistent observations suggest that several aspects of the traditional view of SCD origin do not apply. First, diastolic dysfunction, rather than left ventricular systolic dysfunction, predominates 


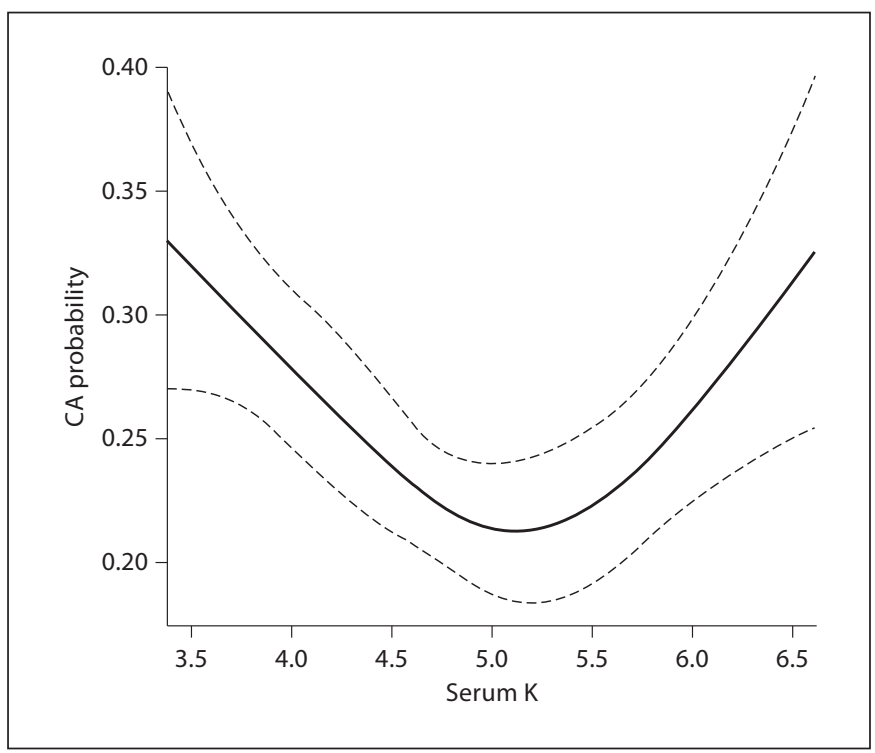

Fig. 2. Risk of cardiac arrest (CA) by last determined predialysis serum potassium (serum $\mathrm{K}$ ) concentration (mEq/l) [24].

in the population of patients with CKD who experience SCD. Two case series of hemodialysis patients found that less than $20 \%$ of SCD victims had a documented left ventricular ejection fraction of less than $35 \%$, whereas left ventricular hypertrophy was seen in more than $70 \%$ of cases $[10,17]$. This is not completely inconsistent with prior observations that link an increase in left ventricular mass with risk of SCD in the general population [6]. Patterns of myocardial scar patterns also differ substantially in dialysis patients compared to nondialysis patients. A more diffuse pattern of myocardial fibrosis is often seen in hemodialysis patients $[18,19]$, and this pattern occurs in the absence of significant coronary artery occlusive disease [6]. This may be the result of multiple factors uniquely present in dialysis patients, such as microvessel disease and capillary deficit (capillary/myocyte mismatch) [20], disorders of mineral metabolism and secondary hyperparathyroidism [21], and repetitive myocardial injury from dialysis-induced myocardial 'stunning' [22].

Patients with advanced CKD who are maintained on hemodialysis are certainly exposed to an array of potential arrhythmic triggers. One time window of enhanced risk is highlighted by consistent observations that SCD occurs most frequently on hemodialysis days, especially on the first hemodialysis day after the long dialysis-free weekend for patients on a thrice-weekly treatment schedule $[10,23]$. Other studies of the hemodialysis procedure consistently highlight an association between extreme values of serum potassium concentration [24], exposure to low potassium and calcium dialysate [24, 25], and rapid ultrafiltration rate $[26,27]$ with an increased risk of cardiovascular mortality and SCD (fig. 2). Electrocardiographic parameters related to ventricular repolarization, such as an increase in QT interval dispersion and QT interval prolongation, worsen over the course of a dialysis treatment [28]. These changes have been shown to be influenced by exposure to low calcium and potassium during hemodialysis, and have been independently associated with cardiovascular mortality in dialysis patients, although they are yet to be specifically linked to a SCD risk [29]. Interaction of these triggering factors with specific genetic loci as determinants of SCD risk in hemodialysis patients has not been studied.

Dialysis patients are also subject to a variety of conditions that might create other mechanisms, distinct from the cardiovascular system itself, which can cause sudden death. Unique dialysis-specific complications such as hyperkalemia, air embolism, exsanguination from vascular access, and other noncardiac mechanisms could easily be mistaken for a cardiac event. There is a lack of data describing the overall contribution of noncardiac mechanisms to the overall sudden death rate, but a small autopsy series of Japanese dialysis patients found stroke as the most frequent cause of sudden death (25.8\%), followed by cardiac disease (19\%), and infectious disease (17.2\%) [30]. Further evidence of the role of noncardiac sudden death in hemodialysis patients comes from small retrospective studies of presenting arrhythmias in cardiac arrest events. These suggest that as few as 19\% of cardiac arrests are instigated by ventricular arrhythmias, whereas nonventricular terminal arrhythmias due to metabolic derangements or other noncardiac catastrophes may play a greater role $[10,15,25,31]$. Investigation into characterization of SCD arrhythmias in hemodialysis patients is sorely needed since nonventricular arrhythmias would not be expected to respond to traditional resuscitative measures involving defibrillation [32].

\section{Prevention/Management of SCD Risk}

Unfortunately, there are no randomized clinical trials of interventions to reduce SCD in hemodialysis patients to date. Definitive studies will be needed to develop effective strategies to manage the problem of SCD, but recommendations can be developed based on existing evidence from observational studies. 
Given the exaggerated risk of SCD in hemodialysis patients, and the abysmal long-term survival rate following a cardiac arrest [33], primary prevention of SCD should be a major priority. This begins with identification of high-risk patients, but efforts to risk-stratify are hampered by the fact that most of the risk factors described above have only weak associations with SCD in small cohorts of patients. Even though traditional risk predictors such as low ejection fraction have been associated with SCD in some dialysis cohorts [2], day-to-day changes in volume status makes this more difficult to assess in dialysis patients, and its predictive value is markedly reduced given the predominance of diastolic rather than systolic heart dysfunction in hemodialysis patients. Potential biomarkers with reported associations with SCD among dialysis patients include markers of inflammation (IL-6 [13], C-reactive protein [13], and adiponectin [34]) and nutrition (serum albumin [13] and predialysis serum creatinine [24]), but these factors have not been validated across cohorts. Furthermore, it is unclear how any of these risk factors should be weighted in determining overall risk [35]. In spite of these deficiencies, some general assumptions can reasonably be made about the profile of the high-risk hemodialysis patient based on demographic, comorbid, clinical, and behavioral risk factors. Patients who are incident to maintenance hemodialysis and those with advanced dialysis vintage should be considered high-risk populations. Victims of SCD are commonly diabetic and have a history of arrhythmias and pre-existing heart disease [36]. Patients who are prone to large interdialytic weight gains, extremes of serum potassium level, and those who fall far out of the desired target ranges for mineral metabolism and nutrition also form the general profile of the high-risk patient $[24,37]$.

A reasonable strategy to reduce $S C D$ events would be to target high-risk patients for prevention using cardiovascular medications and modification of the dialysis prescription. $\beta$-Adrenergic blockers have been shown to reduce SCD after myocardial infarction, but their utility for this purpose in hemodialysis patients remains unclear. Hemodialysis patients prescribed $\beta$-blockers were observed to have improved survival after cardiac arrest [38], and a randomized study of carvedilol among 114 hemodialysis patients with dilated cardiomyopathy showed an overall $24 \%$ reduction in mortality at 2 years, and a trend towards a significant reduction in SCD [39]. However, in a recent secondary analysis of the HEMO study, $\beta$-blocker use was not associated with a decreased risk of SCD [40].
The overall benefit of cholesterol-lowering medications was recently suggested by the results of the Study of Heart and Renal Protection (SHARP) [41]. In SHARP, patients with CKD (including approximately a third of patients on dialysis) who were treated with simvastatin and ezetimibe experienced significantly fewer cardiovascular events than CKD patients who did not receive cholesterol-lowering medications. However, CKD patients in SHARP who received the cholesterol-lowering medications did not show evidence for a reduction in all-cause mortality [41].

The effect of renin-angiotensin system blockers on cardiovascular outcomes has been poorly studied in hemodialysis patients. It is noteworthy, however, that the benefits associated with the use of angiotensin receptor blockers were more pronounced for markers of progression of kidney disease, and angiotensin receptor blockers did not substantially influence overall mortality in diabetic nephropathy [42]. These observations suggest that classes of medications that effectively lower cardiovascular risk in the general population may have a more muted effect in patients with advanced CKD.

Greater attention to detail in determining the dialysis prescription and avoidance of large electrolyte and fluid volume shifts are critical to reduce the risk of SCD in patients with end-stage kidney disease. Elimination or limited use of low or no potassium dialysate from the outpatient dialysis center is supported by two large cohort studies $[24,25]$. It is important to note that in these studies examining mean predialysis serum potassium levels have typically been in the normal range, suggesting that regular review and adjustment of dialysis prescription in response to laboratory data may be simple steps to reduce the risk of SCD. Risk associations with higher ultrafiltration targets should be added incentive to redouble efforts to promote patient compliance with interdialytic weight gain. Evolving data also supports the reduction of dialysate to serum sodium gradient as a means to reduce weight gain [43]. It remains to been seen if frequent or long slow hemodialysis or other modifications to improve the tolerability of the dialysis procedure will prove beneficial in preventing SCD, although the reductions in left ventricular mass that were observed in clinical trials are cause for optimism [44].

The role of implantable cardioverter defibrillators (ICDs) for prevention in SCD in hemodialysis patients is more controversial. ICDs are a proven but expensive therapy to reduce SCD and overall mortality in patients at risk without kidney disease. Although it seems appealing to manage the epidemic of SCD in hemodialysis patients with this therapy, there is a lack of evidence supporting 
Table 1. Possible strategies for SCD prevention in the high-risk patient

\begin{tabular}{|c|c|}
\hline Strategy & Possible intervention \\
\hline \multicolumn{2}{|c|}{ Reduce the progression of cardiomyopathy } \\
\hline Systolic heart dysfunction & $\begin{array}{l}\text { Assess left ventricular systolic and diastolic function within } 3 \text { months of dialysis initiation and } \\
\text { every } 3 \text { years thereafter }\end{array}$ \\
\hline $\begin{array}{l}\text { Diastolic heart dysfunction } \\
\text { (left ventricular hypertrophy) }\end{array}$ & $\begin{array}{l}\text { Use carvedilol in patients with dilated cardiomyopathy; } \\
\text { consider frequent hemodialysis to reduce left ventricular mass }\end{array}$ \\
\hline \multicolumn{2}{|c|}{ 2. Minimize dialysis-related arrhythmic triggers } \\
\hline Potassium shifts & $\begin{array}{l}\text { Monitor potassium more frequently especially after hospitalization, and change dialysis } \\
\text { prescription accordingly; avoid low-potassium baths }(<2 \mathrm{meQ} / \mathrm{l})\end{array}$ \\
\hline Calcium shifts & Avoid low-calcium baths, especially in the context of concurrent use of QT-prolonging medications \\
\hline Rapid ultrafiltration & $\begin{array}{l}\text { Encourage patient compliance with fluid restriction between treatments; } \\
\text { avoid sodium ramping and large dialysate/serum sodium gradients; } \\
\text { extend dialysis time to reduce ultrafiltration rate }\end{array}$ \\
\hline 3. Use ICDs & $\begin{array}{l}\text { Consider ICDs for secondary prevention; } \\
\text { more data needed to support efficacy of prophylactic ICD implantation; } \\
\text { consider associated vascular and infectious risks }\end{array}$ \\
\hline
\end{tabular}

safety and efficacy of ICDs in this population. Multiple authors have reported increased mortality and an increased complication rate in dialysis ICD recipients compared to nondialysis recipients [45-47]. An often overlooked complication of ICDs germane to this population is the potential for intravascular leads to promote central venous stenosis and vascular access compromise [48]. A recent study by Charytan et al. [49] examined all hemodialysis patients enrolled in the Medicare program in the United States who received a defibrillator device between 1994 and 2006. The annual mortality for the 9,528 study patients was disturbingly high at $45 \%$, and the majority of deaths were attributed to arrhythmic causes (38\%). The rate of infection was also alarming, with high annual rates of bacteremia (52\%) and device infection (4.2\%). This study also highlights the growing number of dialysis patients who receive primary prevention ICDs in the absence of trial data supporting efficacy in this population. Of note, comparison of hemodialysis patients receiving a secondary prevention ICD (i.e. after sustaining and surviving a cardiac arrest) with a propensity-matched control group revealed a significant survival advantage associated with ICD implantation (HR: 0.86), although the benefit appears to diminish after 3 years. Even though this analysis is subject to bias by indication, it corroborates previous findings suggesting a modest survival benefit with secondary prevention ICDs [50].

A summary of potential preventative strategies for patients at high risk for SCD is listed in table 1.

\section{Conclusion}

SCD is a major problem in hemodialysis patients, and our understanding of this disease is underdeveloped. Well-designed cohort studies will be needed for a basic understanding of the disease pathophysiology and risk factors, and randomized intervention trials will be needed before new and effective management practices can be developed. With the current compendium of observations, a common sense approach to SCD prevention should be to target patients at highest risk for treatment with existing cardiovascular medications and to reduce and monitor potential dialysis-related arrhythmic triggers. Other unproven cardiovascular therapies such nonconventional dialysis modalities or ICDs should be used judiciously and on a case-by-case basis, with recognition of the associated hazards that these approaches carry in the vulnerable population of patients who are treated with maintenance hemodialysis.

References

Blood Purif 2012;33:183-189
1 USRDS Annual Data Report. Bethesda, National Institutes of Health, National Institute of Diabetes and Digestive and Kidney Diseases, 2006.

2 Wang AY, Lam CW, Chan IH, Wang M, Lui SF, Sanderson JE: Sudden cardiac death in end-stage renal disease patients: a 5-year prospective analysis. Hypertension 2010;56: 210-216. 
3 USRDS Annual Data Report. Bethesda, National Institutes of Health, National Institute of Diabetes and Digestive and Kidney Diseases, 2010.

4 Myerburg RJ, Catellanos A: Cardiac arrest and sudden cardiac death; in Zipes DP, Libby $\mathrm{P}$, Bonow RO, Braunwald E (eds): Braunwald's Heart Disease: A Textbook of Cardiovascular Medicine. Philadelphia, Elsevier Saunders, 2005, pp 865-908.

5 Pratt CM, Greenway PS, Schoenfeld MH, Hibben ML, Reiffel JA: Exploration of the precision of classifying sudden cardiac death. Implications for the interpretation of clinical trials. Circulation 1996;93:519-524.

-6 Zipes DP, Camm AJ, Borggrefe M, Buxton AE, Chaitman B, Fromer M, Gregoratos G, Klein G, Moss AJ, Myerburg RJ, Priori SG, Quinones MA, Roden DM, Silka MJ, Tracy C, Smith SC Jr, Jacobs AK, Adams CD, Antman EM, Anderson JL, Hunt SA, Halperin JL, Nishimura R, Ornato JP, Page RL, Riegel B, Blanc JJ, Budaj A, Dean V, Deckers JW, Despres C, Dickstein K, Lekakis J, McGregor K, Metra M, Morais J, Osterspey A, Tamargo JL, Zamorano JL: ACC/AHA/ESC 2006 guidelines for management of patients with ventricular arrhythmias and the prevention of sudden cardiac death: a report of the American College of Cardiology/American Heart Association Task Force and the European Society of Cardiology Committee for Practice Guidelines (Writing Committee to Develop Guidelines for Management of Patients with Ventricular Arrhythmias and the Prevention of Sudden Cardiac Death): developed in collaboration with the European Heart Rhythm Association and the Heart Rhythm Society. Circulation 2006;114:e385-e484

7 Ritz E, Wanner C: The challenge of sudden death in dialysis patients. Clin J Am Soc Nephrol 2008;3:920-929.

-8 Rocco MV, Yan G, Gassman J, Lewis JB, Ornt D, Weiss B, Levey AS: Comparison of causes of death using HEMO study and HCFA endstage renal disease death notification classification systems. The National Institutes of Health-Funded Hemodialysis. Health Care Financing Administration. Am J Kidney Dis 2002;39:146-153.

9 Pun P, Herzog CA, Middleton J: Improving ascertainment of sudden cardiac death in end stage renal disease. Clin J Am Soc Nephrol 2011, E-pub ahead of print.

-10 Bleyer AJ, Hartman J, Brannon PC, ReevesDaniel A, Satko SG, Russell G: Characteristics of sudden death in hemodialysis patients. Kidney Int 2006;69:2268-2273.

-11 Wanner C, Krane V, Marz W, Olschewski M, Mann JF, Ruf G, Ritz E: Atorvastatin in patients with type 2 diabetes mellitus undergoing hemodialysis. N Engl J Med 2005;353: 238-248.

-12 Cheung AK, Sarnak MJ, Yan G, Berkoben M, Heyka R, Kaufman A, Lewis J, Rocco M, Toto $\mathrm{R}$, Windus D, Ornt D, Levey AS: Cardiac diseases in maintenance hemodialysis patients: results of the HEMO study. Kidney Int 2004 65:2380-2389.

13 Parekh RS, Plantinga LC, Kao WH, Meoni LA, Jaar BG, Fink NE, Powe NR, Coresh J, Klag MJ: The association of sudden cardiac death with inflammation and other traditional risk factors. Kidney Int 2008;74:1335-1342.

14 Genovesi S, Valsecchi MG, Rossi E, Pogliani D, Acquistapace I, De Cristofaro V, Stella A, Vincenti A: Sudden death and associated factors in a historical cohort of chronic haemodialysis patients. Nephrol Dial Transplant 2009;24:2529-2536.

15 Huikuri HV, Castellanos A, Myerburg RJ Sudden death due to cardiac arrhythmias. N Engl J Med 2001;345:1473-1482.

16 Spooner PM: Sudden cardiac death: the larger problem... the larger genome. J Cardiovasc Electrophysiol 2009;20:585-596.

17 Mangrum AJ, Liu D, Dimarco JP, Bolton K, Mangrum M: Sudden cardiac death and left ventricular function in hemodialysis patients. Heart Rhythm 2005;2:S41.

18 Mark PB, Johnston N, Groenning BA, Foster JE, Blyth KG, Martin TN, Steedman T, Dargie HJ, Jardine AG: Redefinition of uremic cardiomyopathy by contrast-enhanced cardiac magnetic resonance imaging. Kidney Int 2006;69:1839-1845.

19 Schietinger BJ, Brammer GM, Wang $\mathrm{H}$ Christopher JM, Kwon KW, Mangrum AJ, Mangrum JM, Kramer CM: Patterns of late gadolinium enhancement in chronic hemodialysis patients. JACC Cardiovasc Imaging 2008; 1:450-456

20 Amann K, Breitbach M, Ritz E, Mall G: Myocyte/capillary mismatch in the heart of uremic patients. J Am Soc Nephrol 1998;9:10181022

-21 Amann K, Ritz E, Wiest G, Klaus G, Mall G A role of parathyroid hormone for the activation of cardiac fibroblasts in uremia. J Am Soc Nephrol 1994;4:1814-1819.

22 Burton JO, Jefferies HJ, Selby NM, McIntyre CW: Hemodialysis-induced cardiac injury: determinants and associated outcomes. Clin J Am Soc Nephrol 2009;4:914-920.

23 Bleyer AJ, Russell GB, Satko SG: Sudden and cardiac death rates in hemodialysis patients. Kidney Int 1999;55:1553-1559.

24 Pun PH, Lehrich RW, Honeycutt EF, Herzog CA, Middleton JP: Modifiable risk factors associated with sudden cardiac arrest within hemodialysis clinics. Kidney Int 2011;79: 218-227.

25 Karnik JA, Young BS, Lew NL, Herget M, Dubinsky C, Lazarus JM, Chertow GM: Cardiac arrest and sudden death in dialysis units. Kidney Int 2001;60:350-357.

26 Movilli E, Gaggia P, Zubani R, Camerini C, Vizzardi V, Parrinello G, Savoldi S, Fischer MS, Londrino F, Cancarini G: Association between high ultrafiltration rates and mortality in uraemic patients on regular haemodialysis. A 5-year prospective observational multicentre study. Nephrol Dial Transplant 2007;22:3547-3552.
27 Saran R, Bragg-Gresham JL, Levin NW, Twardowski ZJ, Wizemann V, Saito A, Kimata N, Gillespie BW, Combe C, Bommer J, Akiba T, Mapes DL, Young EW, Port FK: Longer treatment time and slower ultrafiltration in hemodialysis: associations with reduced mortality in the DOPPS. Kidney Int 2006;69:1222-1228.

28 Morris ST, Galiatsou E, Stewart GA, Rodger RS, Jardine AG: QT dispersion before and after hemodialysis. J Am Soc Nephrol 1999;10: 160-163.

-29 Beaubien ER, Pylypchuk GB, Akhtar J, Biem HJ: Value of corrected QT interval dispersion in identifying patients initiating dialysis at increased risk of total and cardiovascular mortality. Am J Kidney Dis 2002;39:834842.

- 30 Takeda K, Harada A, Okuda S, Fujimi S, Oh Y, Hattori F, Motomura K, Hirakata H, Fujishima M: Sudden death in chronic dialysis patients. Nephrol Dial Transplant 1997;12: 952-955.

- 31 Davis TR, Young BA, Eisenberg MS, Rea TD, Copass MK, Cobb LA: Outcome of cardiac arrests attended by emergency medical services staff at community outpatient dialysis centers. Kidney Int 2008;73:933-939.

- 32 Lafrance JP, Nolin L, Senecal L, Leblanc M: Predictors and outcome of cardiopulmonary resuscitation (CPR) calls in a large haemodialysis unit over a seven-year period. Nephrol Dial Transplant 2006;21:1006-1012.

33 Lehrich R, Pun PH, Tanenbaum ND, Smith SR, Middleton JP: Automated external defibrillators and survival from cardiac arrest in the outpatient hemodialysis clinic. J Am Soc Nephrol 2007;18:312-320.

-34 Drechsler C, Krane V, Winkler K, Dekker FW, Wanner C: Changes in adiponectin and the risk of sudden death, stroke, myocardial infarction, and mortality in hemodialysis patients. Kidney Int 2009;76:567-575.

35 Passman R, Herzog CA: End-stage renal disease: sudden cardiac death: Stratifying risk in dialysis patients. Nat Rev Nephrol 2011;7: 133-135.

36 Herzog CA: Cardiac arrest in dialysis patients: approaches to alter an abysmal outcome. Kidney Int Suppl 2003;84:S197-S200.

37 Ganesh SK, Stack AG, Levin NW, HulbertShearon T, Port FK: Association of elevated serum $\mathrm{PO}(4), \mathrm{Ca} \times \mathrm{PO}(4)$ product, and parathyroid hormone with cardiac mortality risk in chronic hemodialysis patients. J Am Soc Nephrol 2001;12:2131-2138.

38 Pun P, Lehrich RW, Smith SR, Middleton JP: Predictors of survival following cardiac arrest in outpatient hemodialysis clinics. Clin J Am Soc Nephrol 2007;2:491-500.

39 Cice G, Ferrara L, D’Andrea A, D’Isa S, Di Benedetto A, Cittadini A, Russo PE, Golino P, Calabro R: Carvedilol increases two-year survival in dialysis patients with dilated cardiomyopathy: a prospective, placebocontrolled trial. J Am Coll Cardiol 2003;41: 1438-1444. 
40 Tangri N, Shastri S, Tighiouart H, Beck GJ, Cheung AK, Eknoyan G, Sarnak MJ: Betablockers for prevention of sudden cardiac death in patients on hemodialysis: a propensity score analysis of the HEMO study. Am J Kidney Dis 2011, E-pub ahead of print.

-41 Baigent C, Landray MJ, Reith C, Emberson J, Wheeler DC, Tomson C, Wanner C, Krane V, Cass A, Craig J, Neal B, Jiang L, Hooi LS, Levin A, Agodoa L, Gaziano M, Kasiske B, Walker R, Massy ZA, Feldt-Rasmussen B, Krairittichai U, Ophascharoensuk V, Fellstrom B, Holdaas H, Tesar V, Wiecek A, Grobbee D, de Zeeuw D, Gronhagen-Riska C, Dasgupta T, Lewis D, Herrington W, Mafham M, Majoni W, Wallendszus K, Grimm R, Pedersen T, Tobert J, Armitage J, Baxter A, Bray C, Chen Y, Chen Z, Hill M, Knott C, Parish S, Simpson D, Sleight P, Young A, Collins R: The effects of lowering LDL cholesterol with simvastatin plus ezetimibe in patients with chronic kidney disease (study of heart and renal protection): a randomised placebo-controlled trial. Lancet 2011;377: 2181-2192.
42 Brenner BM, Cooper ME, de Zeeuw D, Keane WF, Mitch WE, Parving $\mathrm{HH}, \mathrm{Re}-$ muzzi G, Snapinn SM, Zhang Z, Shahinfar S: Effects of losartan on renal and cardiovascular outcomes in patients with type 2 diabetes and nephropathy. N Engl J Med 2001;345: 861-869.

43 Mendoza JM, Bayes LY, Sun S, Doss S, Schiller B: Effect of lowering dialysate sodium concentration on interdialytic weight gain and blood pressure in patients undergoing thrice-weekly in-center nocturnal hemodialysis: a quality improvement study. Am J Kidney Dis 2011, E-pub ahead of print.

44 In-center hemodialysis six times per week versus three times per week. N Engl J Med 2010;363:2287-2300.

45 Sakhuja R, Keebler M, Lai TS, McLaughlin Gavin C, Thakur R, Bhatt DL: Meta-analysis of mortality in dialysis patients with an implantable cardioverter defibrillator. Am J Cardiol 2009;103:735-741.

46 Dasgupta A, Montalvo J, Medendorp S, Lloyd-Jones DM, Ghossein C, Goldberger J, Passman R: Increased complication rates of cardiac rhythm management devices in ESRD patients. Am J Kidney Dis 2007;49: 656-663.
47 Wase A, Basit A, Nazir R, Jamal A, Shah S, Khan T, Mohiuddin I, White C, Saklayen M, McCullough PA: Impact of chronic kidney disease upon survival among implantable cardioverter-defibrillator recipients. J Interv Card Electrophysiol 2004;11:199-204.

$\checkmark 48$ Drew DA, Meyer KB, Weiner DE: Transvenous cardiac device wires and vascular access in hemodialysis patients. Am J Kidney Dis 2011;58:494-496.

49 Charytan DM, Patrick AR, Liu J, Setoguchi S, Herzog CA, Brookhart MA, Winkelmayer WC: Trends in the use and outcomes of implantable cardioverter-defibrillators in patients undergoing dialysis in the United States. Am J Kidney Dis 2011;58:409-417.

50 Herzog CA, Li S, Weinhandl ED, Strief JW, Collins AJ, Gilbertson DT: Survival of dialysis patients after cardiac arrest and the impact of implantable cardioverter defibrillators. Kidney Int 2005;68:818-825.

51 Pun PH, Smarz TR, Honeycutt EF, Shaw LK, Al-Khatib SM, Middleton JP: Chronic kidney disease is associated with increased risk of sudden cardiac death among patients with coronary artery disease. Kidney Int 2009;76: 652-658. 